\title{
MYOCARDIAL METABOLISM DURING AND AFTER DOUBLE VALVE REPLACEMENT*
}

\author{
Emerson A. Moffitt, M.D., John W. Rosevear, M.D., Sait Tarhan, M.D. and \\ Dwight C. McGoon, M.D. $†$
}

OF THE MANY TYPES OF PATIENTS who undergo open-heart operations, those requiring multiple valve replacement are among the most critically ill. Multivalvular surgery involves longer periods of whole-body perfusion than most cardiac operations. Thus, the sickest people, who are in the most advanced stages of their cardiac disease, must be subjected to the longest perfusions and operations. Hence, we studied the myocardial and whole-body metabolic response in 10 of these patients during, and for three days after, anaesthesia and operation. In five patients, the heart continued to beat during coronary perfusion, and in another five, ventricular fibrillation was present. The group that underwent double valve replacement was compared with a group of previously studied children ${ }^{1}$ and adults $^{2}$ who underwent aortic valve replacement, these being representative of less disabled patients having shorter periods of perfusion.

\section{Patifit Information (Table I)}

All 10 patients had Starr-Edwards ball valves inserted in both mitral and aortic sites. In both the "beating" and "fibrillating" groups, three patients had class rv and two had class III disability by the NYHA classification. Nine of the 10 were taking digitalis and eight diuretics. The "beating" group, or those in whom the heart continued to beat during perfusion, included three women and two men, of mean age 45 years (range 24 to 55 ) and mean body surface of $1.56 \mathrm{sq} \mathrm{m}$ (range 1.41 to 1.68 ). One 52-year-old woman died of a left ventricular infarction 22 hours after operation. A 44-year-old man (to be called patient 5), who had severe failure and pulmonary oedema the day before operation, had low cardiac output and hemiparesis after operation, requiring assisted ventilation. He died on the evening of day 4, and postmortem findings included infarction of the left cerebral hemisphere.

The "fibrillating" group, or those in whom the heart fibrillated during perfusion, consisted of two women and three men, of mean age 41.6 years (range 19 to 59) and mean body surface of $1.78 \mathrm{sq} \mathrm{m}$ (range 1.56 to 2.08). Ventricular fibrillation spontaneously occurred carly in perfusion in two patients and was purposely induced in the other three. One death in this group was that of a 19-year-old man who had a tricuspid annuloplasty, in addition to aortic and mitral replacement.

${ }^{*}$ Read at the meeting of the Canadian Anaesthetists' Society, Winnipeg, 22 June 1970.

This investigation was supported in part by Research Grant GM-14919 from the National Institutes of Health. Public Health Service.

† Mayo Clinic and Mayo Foundation, Rochester, Minnesota. Department of Anesthesiology (Drs. Moffitt and Tarhan), of Biochemistry (Dr. Rosevear), and of Surgery (Dr. McGoon). 
TABLE I

Clinical Data on 10 Patients Who Lnderwent Double Valve Replacement

\begin{tabular}{lll}
\hline & $\begin{array}{c}\text { Group with } \\
\text { beating heart } \\
\text { (five patients) }\end{array}$ & $\begin{array}{c}\text { Group with } \\
\text { fibrillating heart } \\
\text { (five patients) }\end{array}$ \\
\hline $\begin{array}{l}\text { Mean age, yr. } \\
\text { (range) }\end{array}$ & 45 & 41.6 \\
Sex & $(24-55)$ & $(19-59)$ \\
Mean surface, sq m & $3 \mathrm{~F}, 2 \mathrm{M}$ & $2 \mathrm{~F}, 3 \mathrm{M}$ \\
$\quad$ (range) & 1.56 & 1.78 \\
$\begin{array}{c}\text { Mean perfusion time, } \\
\text { min (range) }\end{array}$ & $(1.41-1.68)$ & $(1.56-2.08)$ \\
No. on digitalis & 130 & 126 \\
No. on diuretics & 4 & $(102-142)$ \\
No. in NyHA class & 4 & 5 \\
& $2, \mathrm{III}$ & 4 \\
Deaths & $3, \mathrm{IV}$ & $2, \mathrm{III}$ \\
\hline
\end{tabular}

Ventricular hyperirritability developed several hours after extubation on day 2. He was resuscitated from ventricular fibrillation but died 8 hours later.

\section{Details of the Study}

Anaesthesia was maintained with nitrous oxide, oxygen, and a small concentration of halothane, with intermittently administered succinylcholine. During perfusion, halothane was vaporized into the pump-oxygenator, while the patient's lungs were statically inflated with equal volumes of helium and oxygen. All patients were extubated at the end of anaesthesia, except for the three who subsequently died.

All perfusions were done with the vertical-sheet pump-oxygenator primed with diluted acid-citrate-dextrose blood. A standard priming volume was used of 2,500 $\mathrm{ml}$ of blood, diluted with 5 per cent dextrose in 0.45 per cent $\mathrm{NaCl}(750 \mathrm{ml})$, $0.3 \mathrm{M}$ тнам $(330 \mathrm{ml})$, potassium chloride $(20 \mathrm{mEq})$, calcium chloride $(2.5 \mathrm{gm})$, and heparin (15,000 units). Perfusions were at $30^{\circ} \mathrm{C}$, with mean arterial flows of 2.4 and 2.2 liters $/ \mathrm{min} / \mathrm{sq} \mathrm{m}$ for the "beating" and "fibrillating" groups. Mean duration of perfusion for the "beating" group was 130 minutes (range 116 to 149) and for the "fibrillating" group, 126 minutes (range 102 to 142). Both coronary arteries were perfused with separate pumps while the aorta was open, with total coronary flow approximately 5 to 10 per cent of arterial flow. The left coronary pump was volumetrically calibrated after each perfusion because left coronary flow was used to calculate left ventricular oxygen consumption.

Blood was taken from the femoral artery, as a control, before induction of anaesthesia, with the patient breathing air. After induction, a percutaneous transfemoral catheter was inserted into the aorta. After thoracotomy, the surgeon catheterized the coronary sinus, initially transatrially, and then, before the end of perfusion, through the wall of the sinus on the posterior aspect of the heart. Paired arterial and coronary sinus samples were taken before perfusion, during operation, 
and for the succeeding three days, as shown in the figures and tables. After perfusion, left atrial and coronary sinus catheters were brought out through the chest wall near the sternotomy and used for postoperative sampling. The fractional concentration of inspired oxygen before and after perfusion was 0.5 ; at the end of anaesthesia it was 1.0 and after operation approximately 0.3 to 0.5 by a loose facepiece. After operation, the fluid allowance was 500,750 , and $750 \mathrm{ml} / \mathrm{sq} \mathrm{m}$ of 5 per cent dextrose in water for the remainder of day 1 , day 2 , and day 3 . By day 4 , fluids were given orally.

\section{Laboratory ANalyses of Blood}

All samples were iced immediately. Carbon dioxide and oxygen tensions and $\mathrm{pH}$ were measured by electrodes (Instrumentation Laboratories) maintained at $37^{\circ} \mathrm{C}$. Temperature corrections were made when the patient's temperature was below $36^{\circ}$ c, by the Severinghaus blood-gas calculator. ${ }^{3}$ Haemoglobin and haematocrit values werc determined, and buffer base values were read from the SingerHastings nomogram. ${ }^{4}$ Oxygen capacity was obtained (haemoglobin $\times 1.34$ ) and oxygen content, by multiplying the capacity by the oxygen saturation. The latter was measured by an oximeter (American Optical Co). Concentrations of lactate ${ }^{5}$ and pyruvate ${ }^{6}$ were determined by nonenzymatic methods. Values for nonesterified fatty acids (NEFA) ${ }^{\gamma}$ and total ketone bodies ${ }^{8}$ were determined, and glucose was measured by an AutoAnalyzer ${ }^{9}$ (Technicon Instruments). Sodium and potassium levels were done by flame photometry, total calcium level by the Wang method, ${ }^{10}$ and osmolality by freezing point depression (Fiske Osmometer). Because nearly all of coronary sinus blood comes from the left ventricle, ${ }^{11}$ oxygen consumption of the latter during perfusion was calculated by multiplying the left coronary flow (liters $/ \mathrm{min}$ ) by the arterial-coronary sinus difference of oxygen content $(\mathrm{ml} /$ liter $)$.

Student's $t$ test was used for statistical analyses, with $p<0.05$ as the level of significance. Paired data for each variable were compared in each of the "beating" and "fibrillating" groups: (1) arterial to coronary sinus blood levels at each sample time, and (2) each subsequent arterial level to the preinduction control level. Three analyses of unpaired data were done, using arterial concentrations at each sample time: (1) the "beating" group to the "fibrillating" group, (2) all double valves to all aortic valves, ${ }^{2}$ and (3) the "beating" group to the noncyanotic children. ${ }^{1}$

\section{Results}

Mean values (with standard errors) in arterial and coronary sinus blood for all parameters determined, in four patients of the "beating" group, excluding patient 5 , are given in Tables II (during operation) and III (after operation). Comparable information for the five patients in the "fibrillating" group is shown in Tables IV and $\mathrm{V}$ for the operative and postoperative studies. Where standard errors of the mean are not listed, it is because too few numbers were available for analysis.

Figures 1 through 7 depict mean values for the "beating" and "fibrillating" groups, in arterial and coronary sinus blood. Individual values for patient 5 were 


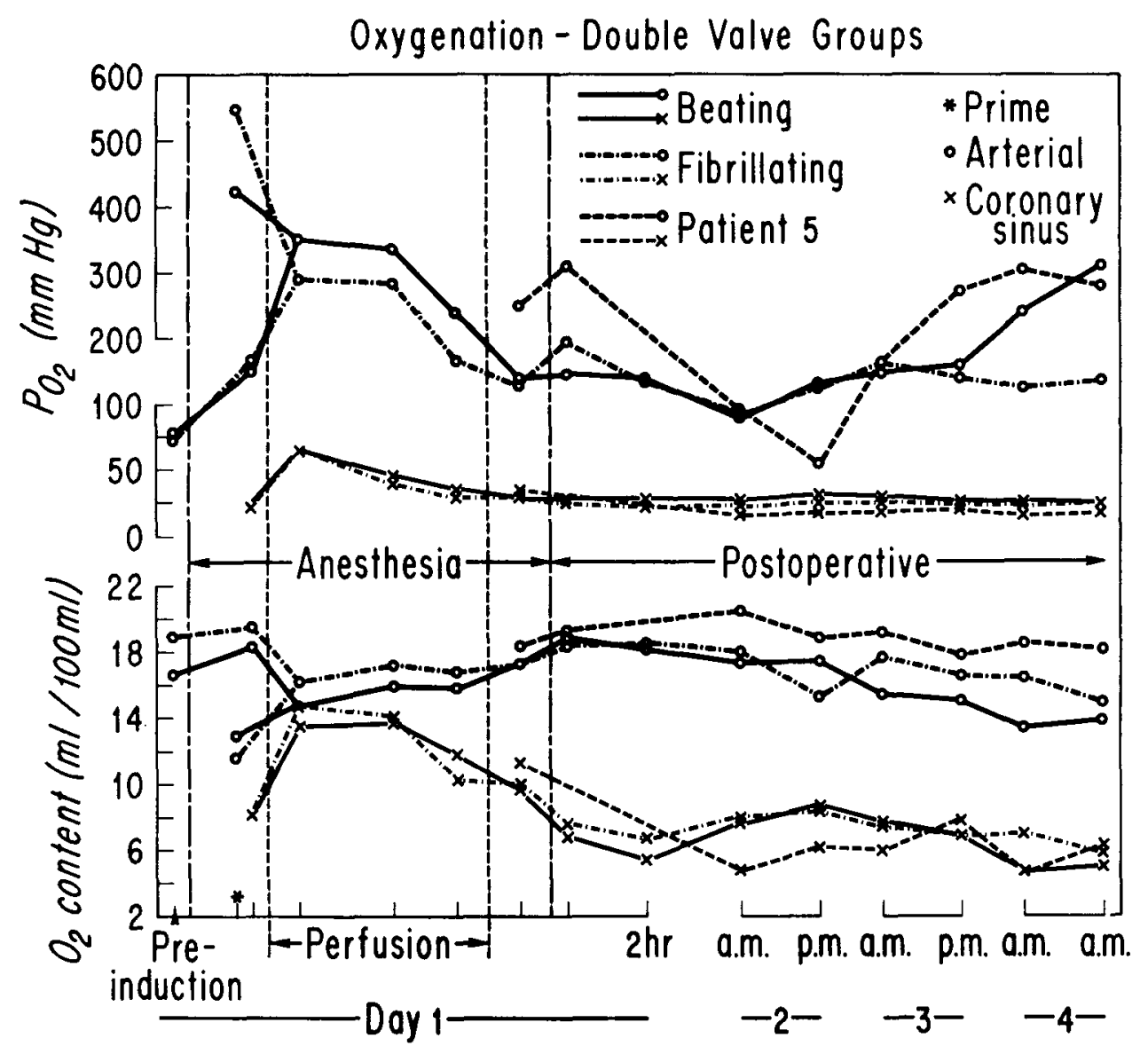

Figure 1. Mean levels of oxygen tension and content for the groups with beating or fibrillating hearts, plus individual values for patient 5 .

also added to each figure when they differed from the mean of the "beating" group. Significant differences across the heart are identified in the figures.

In the "beating" group, the values for many of the parameters increased over control levels during the study. Oxygen content was greater before perfusion, osmolality was higher through perfusion and for one-half hour later, potassium levels were greater early in perfusion, and calcium levels were elevated throughout perfusion and for the remainder of that day. The levels of all of the energyproducing substrates increased over control levels; glucose levels were increased from before perfusion through day 2 , NEFA levels were increased before perfusion and early in perfusion, and total ketone body values were increased on the morning of day 2. Lactate levels were elevated over control levels from before perfusion through the end of operation, and pyruvate levels from early perfusion until the end of operation. The values for a few parameters were lower than control levels during perfusion: oxygen content, from lowered haemoglobin, and sodium levels, from the diluted prime. 


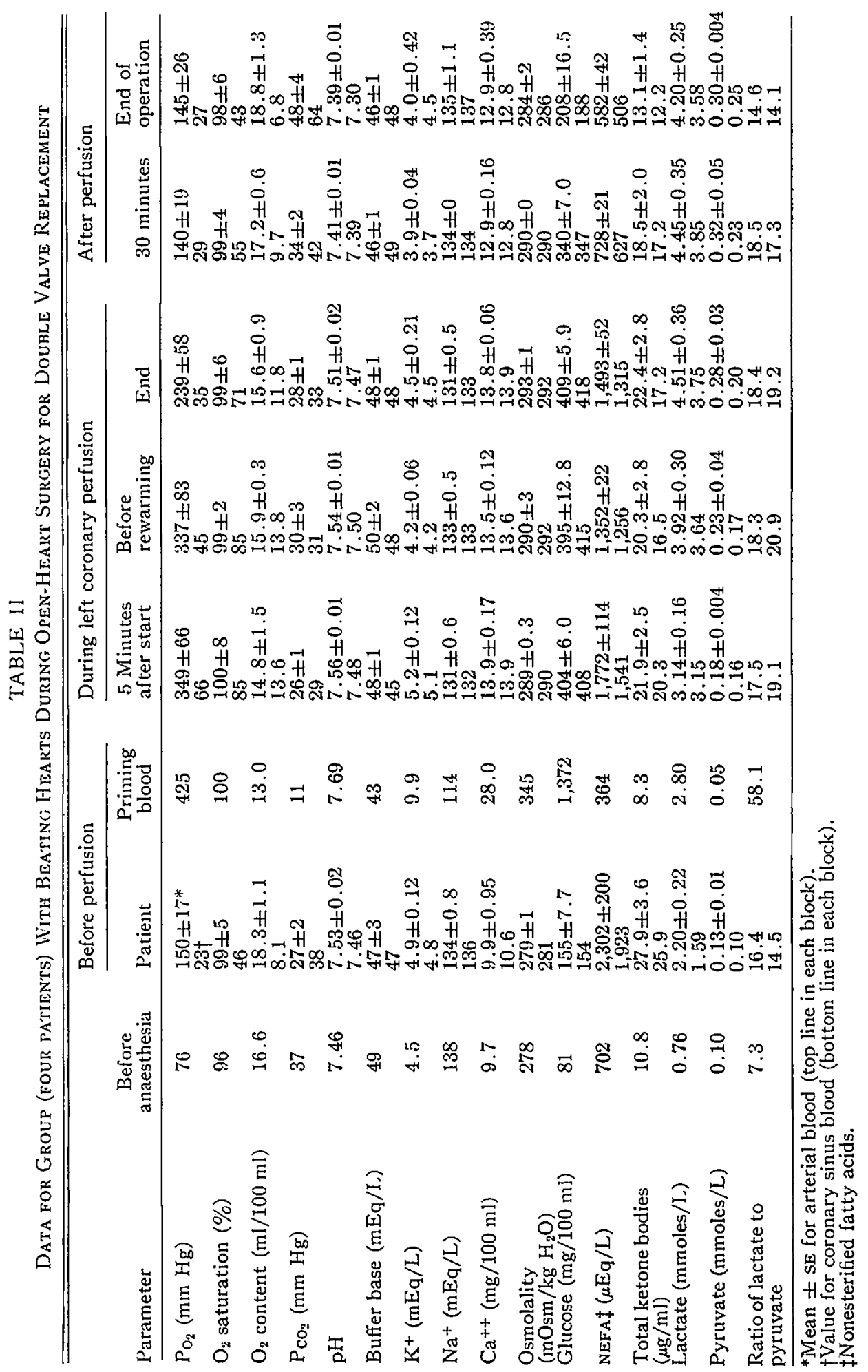




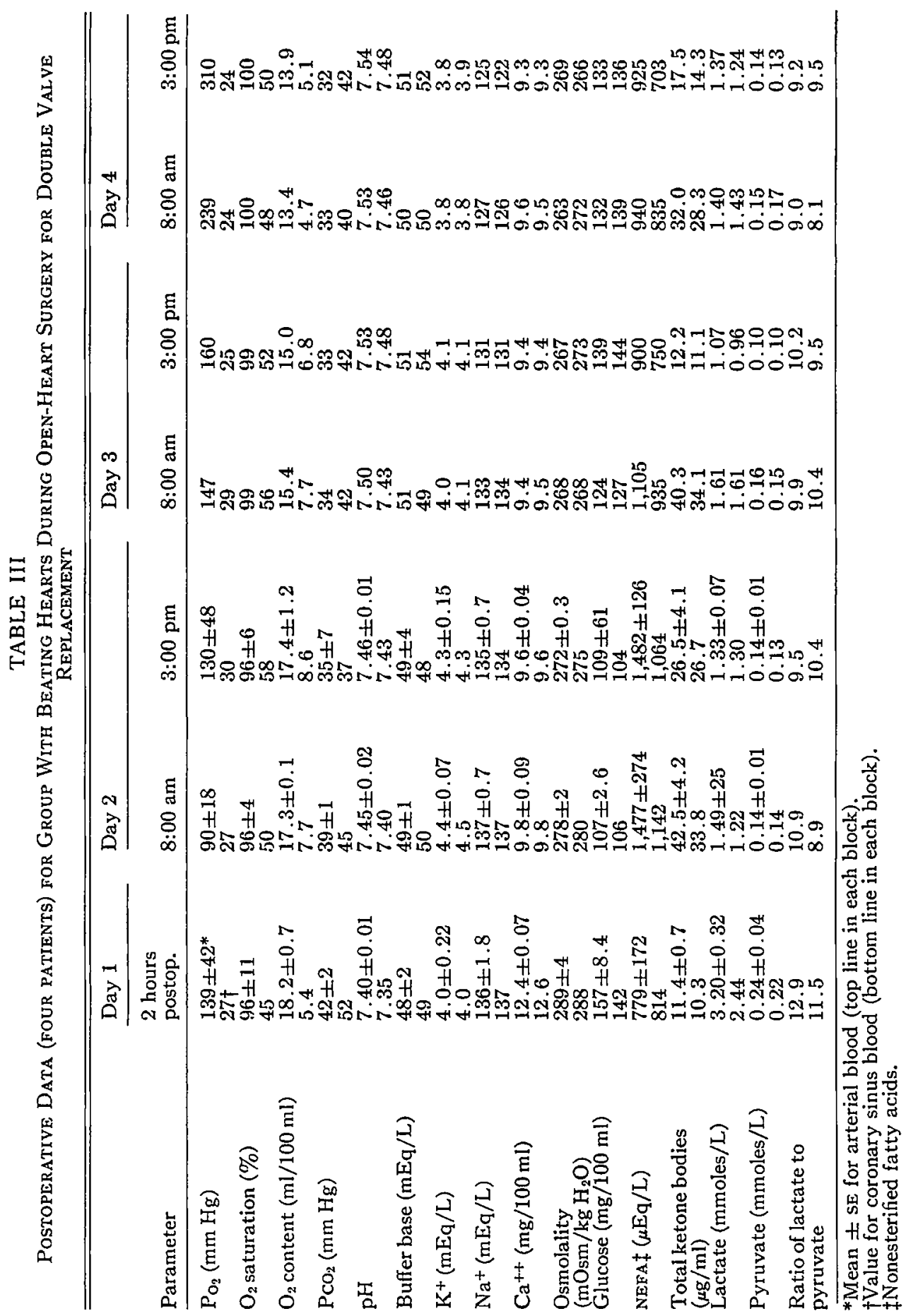




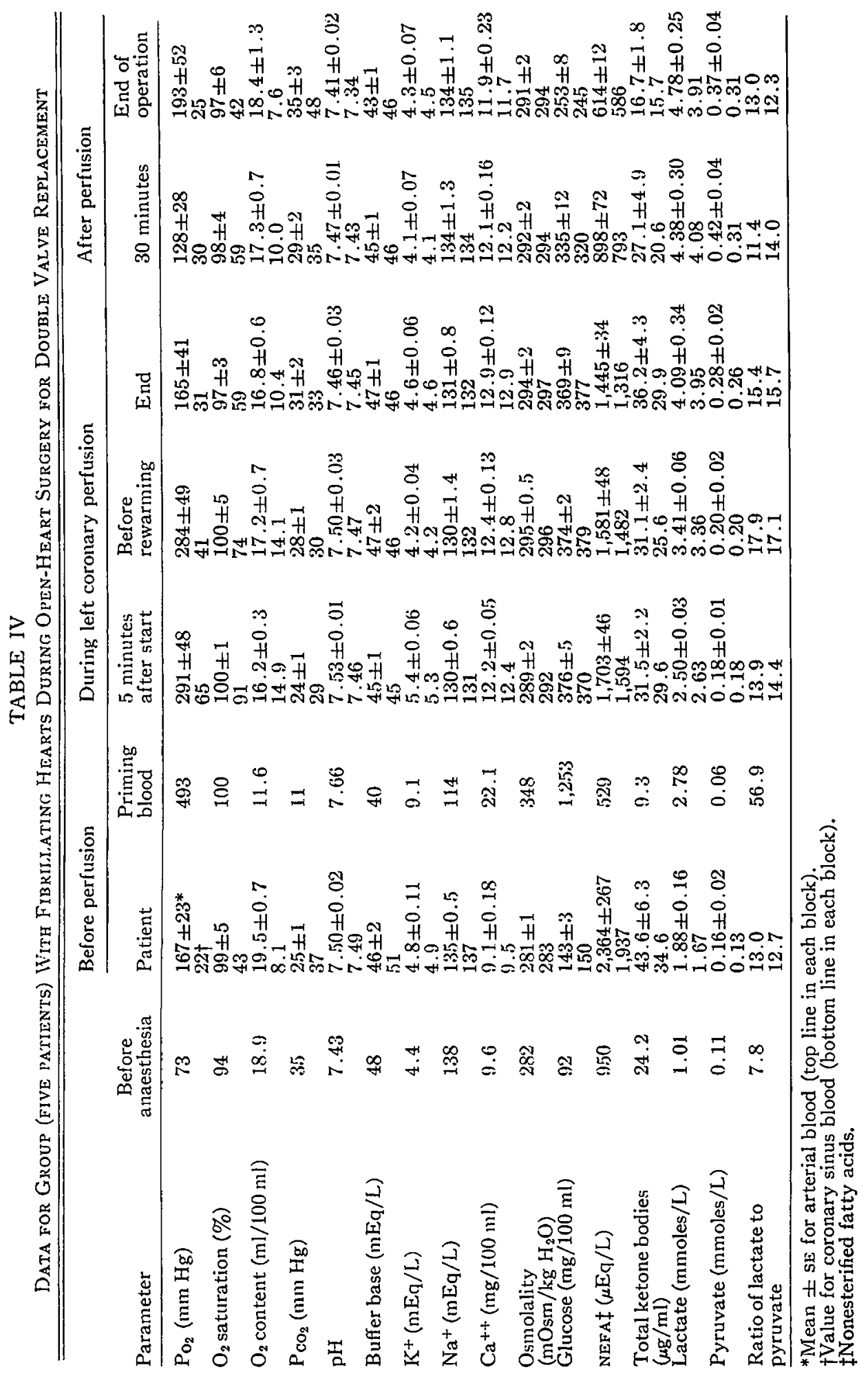




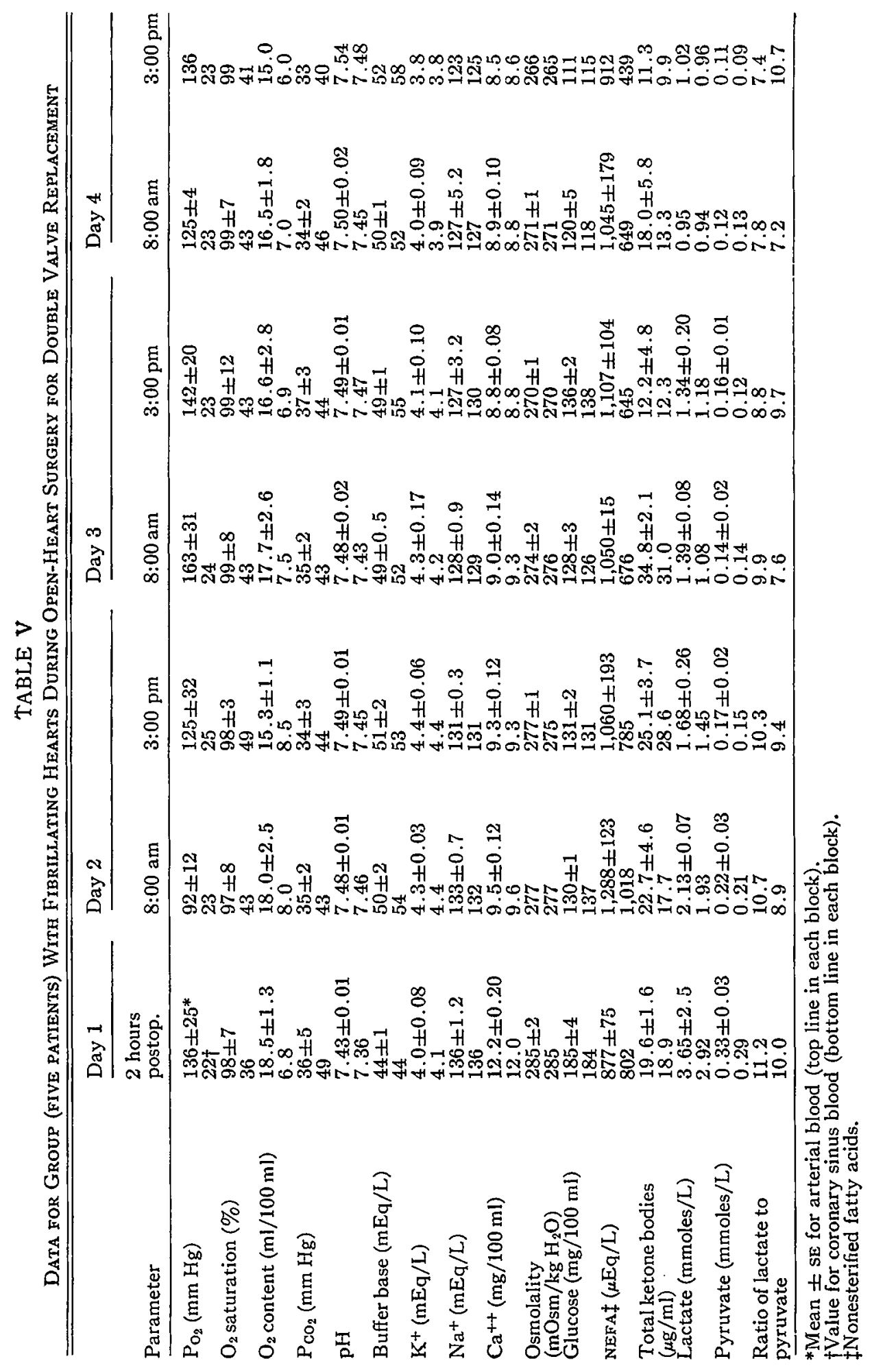




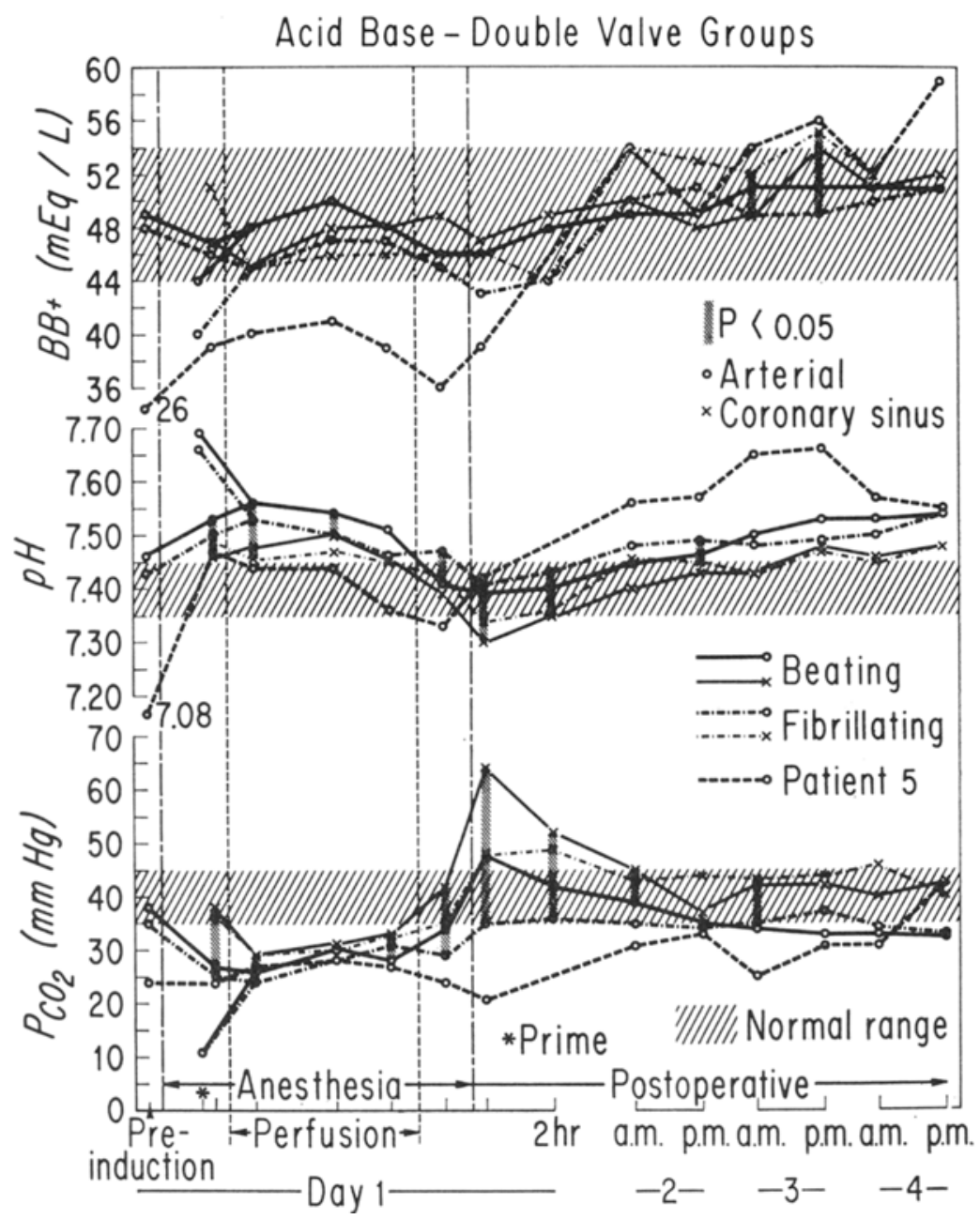

Frgcre 2. Acid-base parameters for the two groups and patient 5, who had metabolic acidosis on day 1 and became alkalotic after operation.

The "fibrillating" group showed similar trends. Haemoglobin values and oxygen content were lower than control values through perfusion. Sodium levels decreased before perfusion, were lower than control values through 2 hours after operation, and decreased again on days 3 and 4 . Osmolality also was below control values on day 4 , but higher during perfusion through the end of operation. Calcium and potassium levels had similar elevations as in the "beating" group. The values for NEFA were higher than control values before, and early in, perfusion, and again on the afternoon of day 2 and morning of day 3. Lactate and pyruvate levels increased from before perfusion through 2 hours after operation. Arterial oxygen tensions were higher than control values before and during perfusion. Total ketone body levels were elevated early in perfusion. 


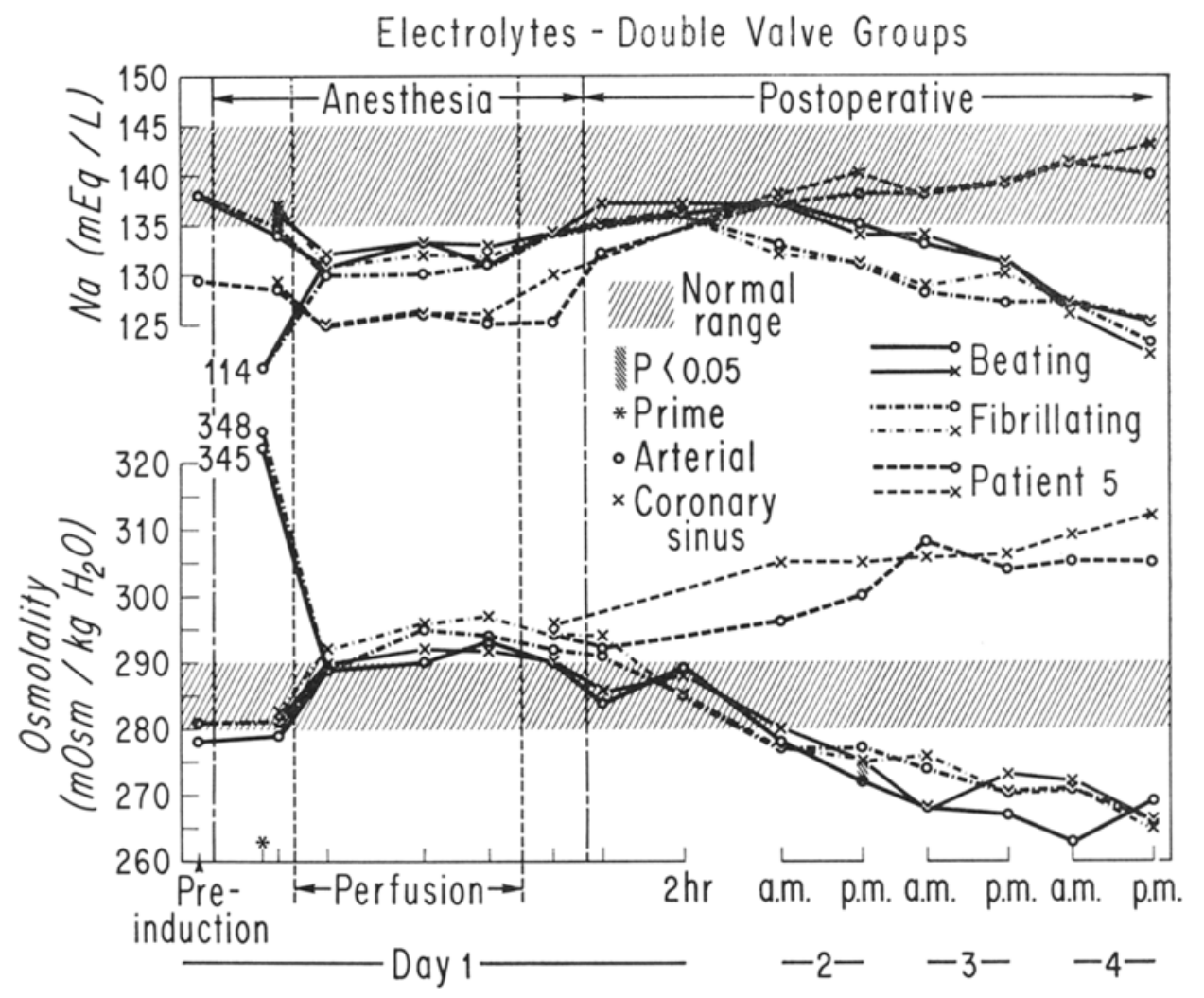

FIGURE 3. Serum sodium and osmolality, mean levels, in the two groups and in patient 5. While the group trends were to hemodilution after operation, patient 5 became hemoconcentrated.

Comparison of the findings in noncyanotic children with those of the adult group with beating hearts revealed several significant differences. $\mathrm{Pa}_{\mathrm{O}_{2}}$ was higher in the adults on the afternoon of day 4 , but lower before induction, at the end of anaesthesia, and on the morning of day $2 . \mathrm{Pa}_{\mathrm{CO}_{2}}$ remained higher in the adults from before perfusion through one-half hour after perfusion. Buffer base values were higher in the adults from before perfusion through perfusion. Thus $\mathrm{pH}$ was higher in the adult group before induction of anaesthesia and also on the afternoon of day 3 plus the morning of day 4 . Potassium levels were higher in the adult group 2 hours after operation and lower on the morning of day 4 . Calcium added to the prime resulted in higher levels in the children during perfusion. The children had higher glucose levels than did the adults before induction and at midperfusion. However, the lactate concentrations of children were less than those of adults on the afternoon of day 2 and morning of day 3.

The two adult groups (double valve group and aortic valve group) ${ }^{2}$ had few significant differences. Oxygen content was higher in the double valve group at midperfusion, but oxygen saturation was lower one-half hour after perfusion. The 
Electrolytes - Double Valve Groups

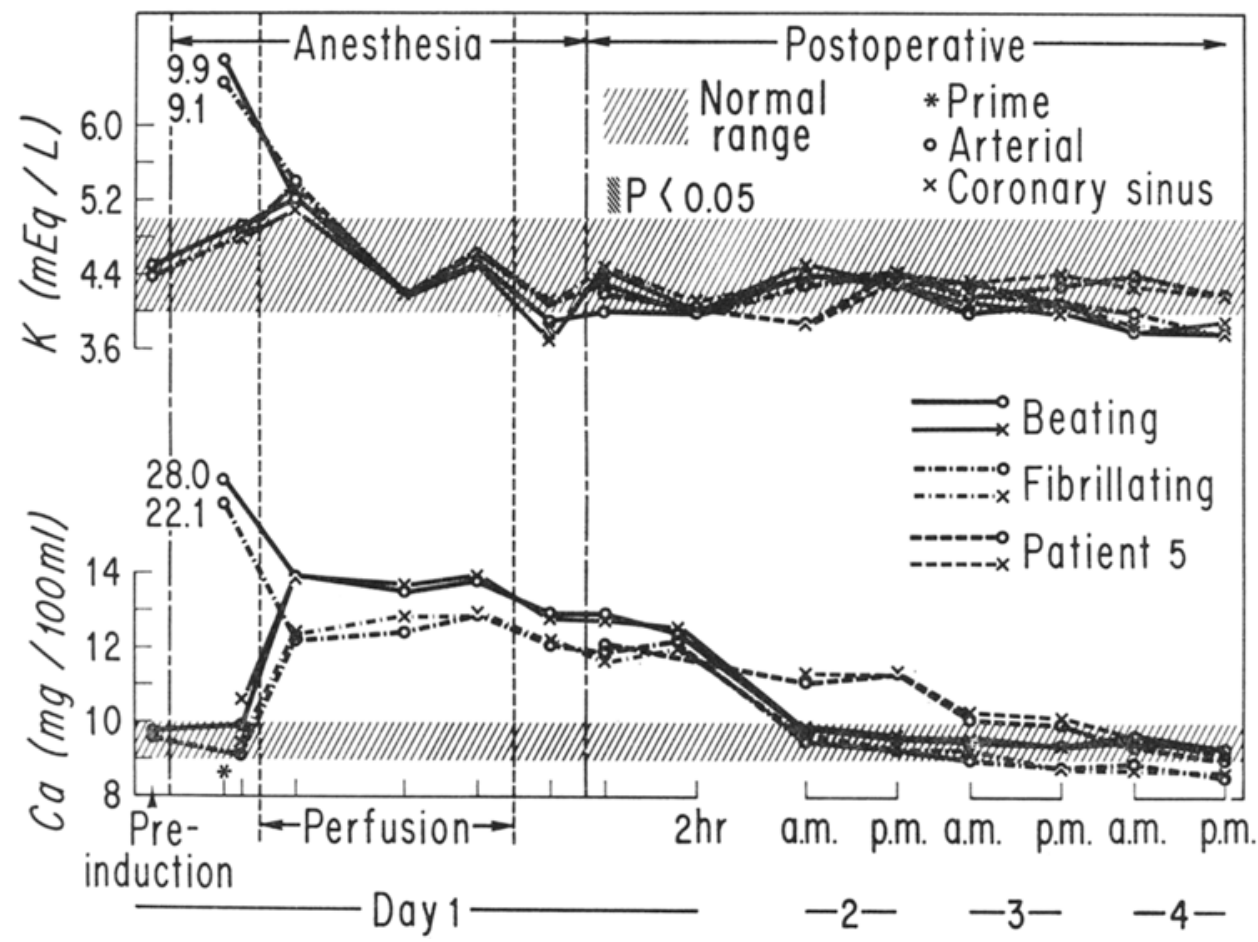

Figure 4. Serum potassium and total calcium in the two groups, and in patient 5. Intergroup differences were not seen.

double valve group had higher $\mathrm{pH}$ before anaesthesia, higher buffer base levels during perfusion, and higher $\mathrm{Pa}_{\mathrm{CO}_{2}}$ at midperfusion. Serum sodium levels were lower in the double valve group on day 4 . Blood glucose levels were higher in the aortic valve group at midperfusion.

The "beating" and "fibrillating" groups undergoing double valve replacement had essentially no significant differences between them in arterial levels of parameters when data from patient 5 were excluded.

Data on left myocardial oxygen consumption during coronary perfusion in the beating and fibrillating hearts are shown in Table VI. The fibrillating left ventricle consistently took up more oxygen at $30^{\circ} \mathrm{C}$ and 34 to $35^{\circ} \mathrm{C}$, at 75 and 100 minutes of direct perfusion, than did the beating heart.

\section{Discussion}

Our objective was to study the most severely ill cardiac patients, those with the longest periods of perfusion. Within this group, we examined the effects of ventricular beating or fibrillation, during coronary perfusion, on myocardial function and metabolism. The two subgroups were alike except for one patient who had been essentially in cardiogenic shock the day before operation. This paper com- 


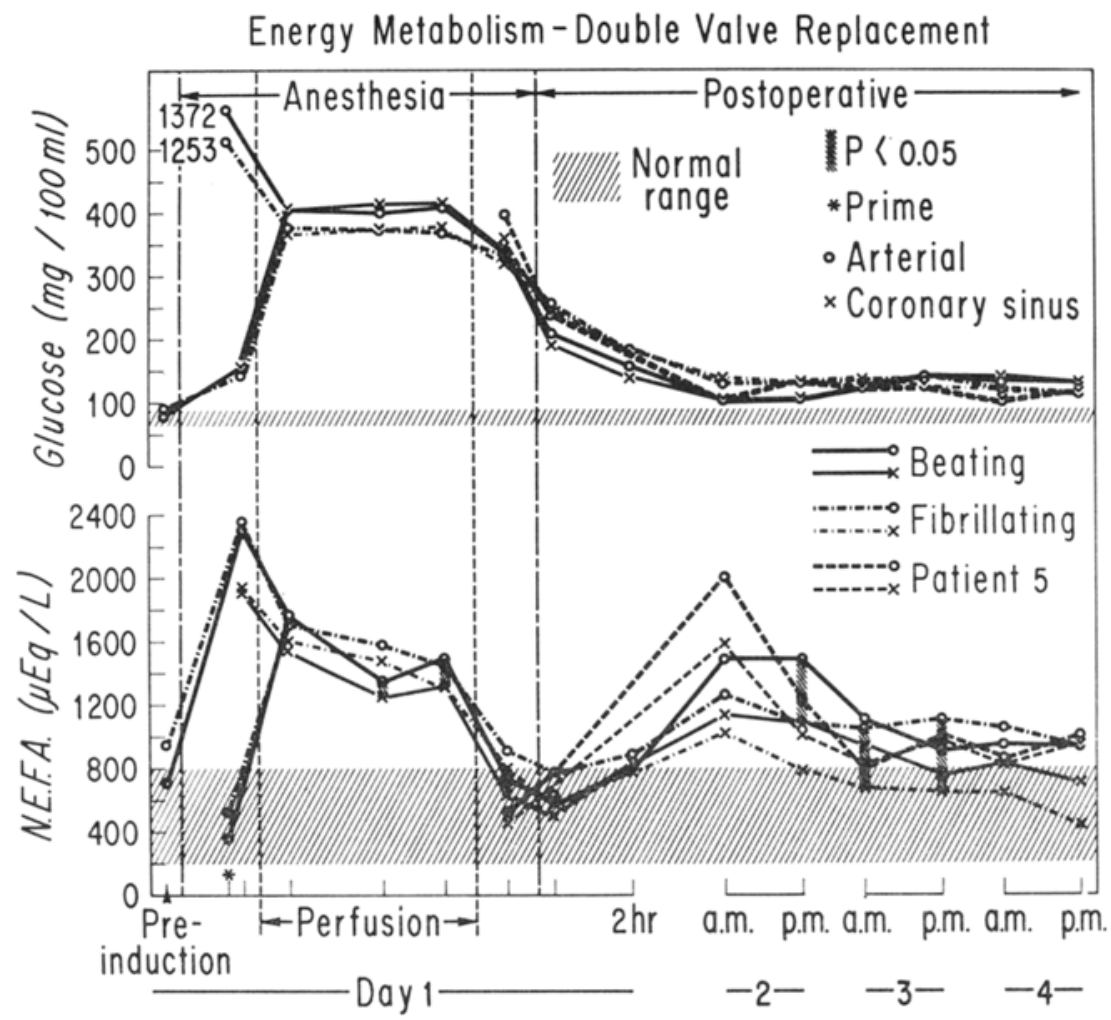

Figure 5. Mean concentrations of glucose and NEFA during and after operation. Glucose was not different between groups. NEFA level was high in patient 5 on the morning after operation.

TABLE VI

Myocardial Oxygen Consumption During Coronary Perfusion for Double Valve REPLACEMENT

\begin{tabular}{|c|c|c|c|c|c|c|}
\hline \multirow[b]{2}{*}{ Mean levels } & \multicolumn{3}{|c|}{$\begin{array}{l}\text { Beating heart } \\
\text { (four patients) }\end{array}$} & \multicolumn{3}{|c|}{$\begin{array}{l}\text { Fibrillating heart } \\
\text { (five patients) }\end{array}$} \\
\hline & Early & $\begin{array}{c}\text { Before } \\
\text { rewarming }\end{array}$ & End & Early & $\begin{array}{l}\text { Before } \\
\text { rewarming }\end{array}$ & End \\
\hline \multirow{4}{*}{$\begin{array}{l}\text { Left coronary flow, } \\
\text { ml/min } \\
\text { Difference* in } \mathrm{O}_{2} \text { content, } \\
\text { ml/100 ml } \\
\text { Oxygen consumption, } \\
\text { ml/min } \\
\text { Body temperature, } \mathrm{c} \\
\text { Duration of left coronary } \\
\text { perfusion, min }\end{array}$} & 203 & 171 & 171 & 208 & 179 & 179 \\
\hline & 1.0 & 2.1 & 4.5 & 1.4 & 4.4 & 7.0 \\
\hline & $\begin{array}{r}2.1 \\
31.1\end{array}$ & $\begin{array}{r}3.5 \\
30.1\end{array}$ & $\begin{array}{r}7.7 \\
34.7\end{array}$ & $\begin{array}{r}3.5 \\
32.4\end{array}$ & $\begin{array}{r}7.8 \\
29.8\end{array}$ & $\begin{array}{l}12.6 \\
34.0\end{array}$ \\
\hline & 5 & 75 & 100 & 5 & 79 & 101 \\
\hline
\end{tabular}

*Arterial minus coronary sinus blood.

pletes the series of studies on the metabolic response of cardiac patients having various lesions repaired by open-heart operations. Investigations of congenital, ${ }^{1}$ aortic, $^{2}$ and mitral $^{12}$ lesions have been published. 


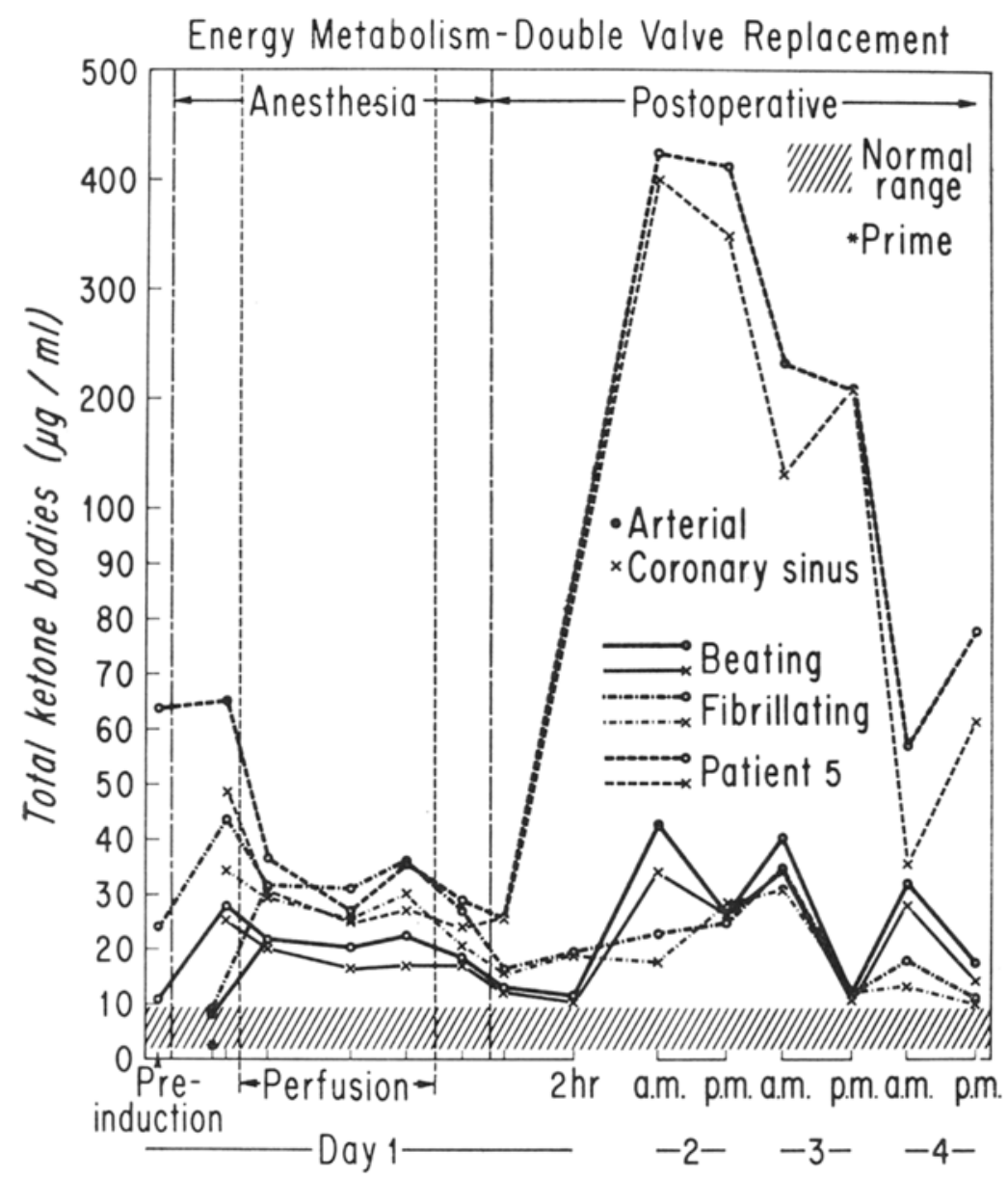

Ficcre 6. Mean levels of total ketone bodies in the "beating" and "fibrillating" groups. Patient 5 had a severely elevated blood level after operation, compared to the two groups.

Oxygenation. Arterial oxygen tension was in general satisfactory in these patients when an elevated $\mathrm{FI}_{\mathrm{O}_{2}}$ was present. When these patients breathe air, $\mathrm{Pa}_{\mathrm{O}_{2}}$ is low because after operation, cardiac output is low normal, and considerable intrapulmonary arteriovenous shunting (patchy atelectasis) is present. A vigorous regimen of deep breathing, frequent turning, and forced coughing, plus intermittent positive-pressure breathing, is invaluable.

As in the group with aortic valve replacement, ${ }^{2}$ we found that the oxygen uptake of the beating left ventricle was less than that of the fibrillating one, under comparable temperatures and coronary flows. After 75 minutes of perfusion at $30^{\circ} \mathrm{C}$, consumption was 46 per cent of that during fibrillation. At 100 minutes of coronary perfusion with partial rewarming, consumption was 60 per cent of the consumption during fibrillation. The trend of continual increase in myocardial oxygen consumption with greater time of hypothermic perfusion, seen in the aortic groups, ${ }^{2}$ was further validated. The patients with aortic valve replacement 


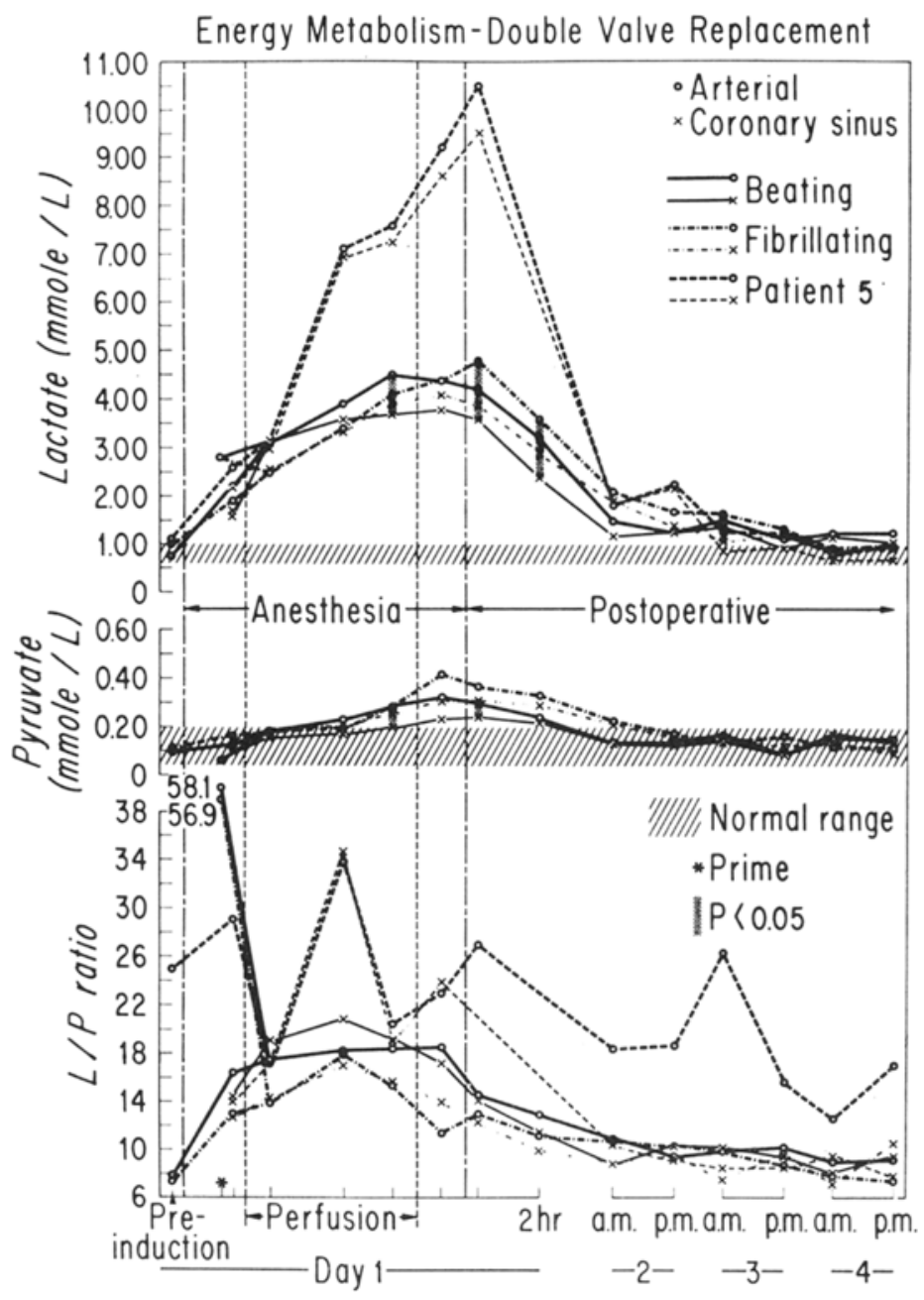

FIGURE 7. Lactate and pyruvate concentrations and $\mathbf{L} / \mathbf{P}$ ratio are shown. Lactate acidosis was greater in patient 5 than in the "beating" or the "fibrillating" group.

had total left ventricular oxygen consumptions of 2.3 (beating) and 8.5 (fibrillating) $\mathrm{ml} / \mathrm{min}$ at 36 minutes of $30^{\circ} \mathrm{C}$ coronary perfusion. Oxygen consumption by the patients with double valve replacement was 3.5 and $7.8 \mathrm{ml} / \mathrm{min}$, respectively, after 75 and 79 minutes of perfusion at $30^{\circ} \mathrm{c}$. These levels of oxygen consumption are still low, compared to the working heart and considering that the left ventricle of those enlarged hearts probably weighed as much as 200 to 300 gm. Oxygen consumption of the normothermic working heart in intact man is approximately 8 to $12 \mathrm{ml} / 100 \mathrm{gm} / \mathrm{min},{ }^{13}$ or about $25 \mathrm{ml} / \mathrm{min}$ for a heart of normal size.

Acid-Base Balance. The findings in the group with double valve replacement were like those in the less ill patients who had shorter perfusions for aortic replacement. $^{2}$ We intentionally produced a respiratory alkalosis during anaesthesia. The THAM and citrate in the priming solution help to avoid metabolic alkalosis, 
even with 2-hour perfusions, and buffer base levels remained well elevated after operation. In contrast, children ${ }^{1}$ who were operated on had less buffering capacity, received more hyperventilation, and resumed a lower $\mathrm{pH}$ after operation than did patients with double valve replacement.

Important to note is the sudden decrease in $\mathrm{pH}$ to normal as $\mathrm{Pa}_{\mathrm{CO}_{2}}$ increased to reinstitute spontaneous breathing at the end of anaesthesia. Myocardial production of carbon dioxide is greatest at that time, and one must be alert for ventricular arrhythmias and inadequate ventilation.

Electrolytes. Electrolyte patterns were similar to those observed in other adult studies. Significant exchanges by the myocardium were not detected. Potassium and calcium were added to the prime, and the level of the latter cation remained elevated for the remainder of the operative day. Potassium levels decreased during the long perfusion but then did not decrease below normal at the end of operation, as they did in the other groups, notably the children. Potassium was lost in considerable amount in the postperfusion diuresis, and likely moved intracellularly as well. Osmolality, an indicator of solute concentration, remained elevated during perfusion, and for several hours later, owing to the electrolytes, glucose, and THAM in the priming solution. Sodium was the only cation found in subnormal concentration, which resulted from the haemodilution, but it regained normality after water was diuresed in the first postoperative hours. A consistent finding was an increase in amount of intravascular water by the third and fourth days, manifested by reduced osmolality and concentration of electrolytes. A generalized retention of body water has been previously demonstrated, ${ }^{14}$ which suggests the advisability of early administration of diuretics to patients who evidence early congestive failure.

Energy Metabolism. Arterial levels of energy substrates for myocardial and whole-body metabolism were elevated both during operation and afterward. NEFA concentrations were highest before perfusion partially due to heparinization of the patient. But NEFA, the form of fat in transit from depots to cells for utilization, is also mobilized by catecholamines and growth hormones during stress. ${ }^{15}$ Arterial levels of NEFA depend on the relative rates of mobilization and utilization; in general, we have not found them greatly elevated after operation. Ketone bodies, produced from NEFA when the liver cannot completely metabolize the amount of NEFA presented to it,$^{16}$ reflect the rate of lipid mobilization. High ketone levels are indicative of carbohydrate deprivation and insulin insensitivity, because administration of glucose, and an insulin increase, causes a change in the fat cell, from NEFA mobilization to its deposit as triglycerides. But epinephrine and growth hormone release throughout this whole period reverse these processes. Glucose utilization by cells is reduced and insulin release by the pancreas is suppressed which, along with glycogenolysis in the liver, raise the blood sugar level. In spite of this increased sugar supply, the body uses it less well. Instead, NEFA is mobilized by the stress hormones, and the body depends predominantly on lipid for energy. The degree of ketonaemia in these more seriously ill patients after operation was not greater than in the less ill group, suggesting that energy production must proceed similarly, in the presence of compensated, even if severe, cardiac disease. 
The increases in lactate and pyruvate concentrations throughout anaesthesia and operation have several possible explanations. Respiratory alkalosis was imposed throughout anaesthesia. ${ }^{17} \mathrm{~A}$ large load of glucose was presented to the body via the priming solution, with its metabolism to pyruvate and lactate ${ }^{17}$ enhanced by THAM ${ }^{18} \mathrm{~A}$ portion of the arterial increase in lactate and pyruvate was possibly due to anaerobic glycolysis in the body, as we have seen significant increases through perfusion and operation using a normal glucose, whole blood prime. ${ }^{19}$ Lactate, pyruvate, and NEFA were utilized by the myocardium when arterial levels were high, but glucose was not.

Cardiogenic Shock. Patient 5 had circulatory inadequacy from severe cardiac failure, with all its metabolic manifestations. His cardiac index before perfusion was 1.13 liters $/ \mathrm{min} / \mathrm{sq} \mathrm{m}$, and $2.71 / \mathrm{sq} \mathrm{m}$ shortly after perfusion. At $3: 00 \mathrm{pm}$ on days 2,3 , and 4 , his indices were $1.46,1.50$, and 1.14 liters $/ \mathrm{min} / \mathrm{sq} \mathrm{m}$, measured by dye dilution, with left atrial injection and aortic sampling. His arterial oxygenation remained satisfactory, particularly after tracheostomy. The greater extraction of oxygen by the myocardium in severe failure is seen from the lower coronary sinus tension and content in patient 5 , especially on day 2 , than in the other patients.

Patient 5 appeared to be acutely vasoconstricted before anaesthesia and had a severe metabolic acidosis, compensated by respiratory alkalosis, but the degree of lactic acidosis was only mild. He remained in base deficit throughout the operation but became progressively more alkalotic after it; the alkalosis was mainly metabolic but also was respiratory. This metabolic alkalosis was largely due to the 4 liters of acid-citrate-dextrose blood given for heavy bleeding during the first hours after perfusion. One striking finding was the much greater production of lactate during and immediately after perfusion. With the same priming solution used for all patients, the outpouring of lactate must indicate generalized anaerobic glycolysis in a still inadequately perfused and oxygenated body. The relative overproduction of lactate is further revealed in the persistently high $\mathrm{L} / \mathrm{P}$ ratios throughout.

The behavior of blood glucose in patient 5 was typical of that of the other patients, except for a myocardial arteriovenous difference of $36 \mathrm{mg} / 100 \mathrm{ml}$ shortly after perfusion, a time in which the serum insulin level is high. ${ }^{20}$ The usual arteriovenous difference in normal man is $3 \mathrm{mg} / 100 \mathrm{ml},{ }^{21}$ and we seldom have found significant differences in patients doing well after perfusion. After operation, the insulin concentration of patient 5 remained between 10 and 24 units $/ \mathrm{ml}$ (normal range 0 to 25), and his blood sugar level was between 101 and $127 \mathrm{mg}$ / $100 \mathrm{ml}$, when sampled (normal 65 to 90 ). That this was insufficient to maintain carbohydrate metabolism is seen from the elevated NEFA levels and extreme ketosis that developed.

The sequence of effects of insulin lack, due to diabetic acidosis, has been depicted by Tepperman ${ }^{16}$ (Figure 8). Profound consequences in carbohydrate, lipid, and protein metabolism occur. The findings in patient 5 followed this course completely, even to the haemoconcentration (rising osmolality and sodium and potassium levels) ultimately followed by hypotension and death. Hence, insulin lack due to its inhibition by catecholamines in acute stress appears to have similar 


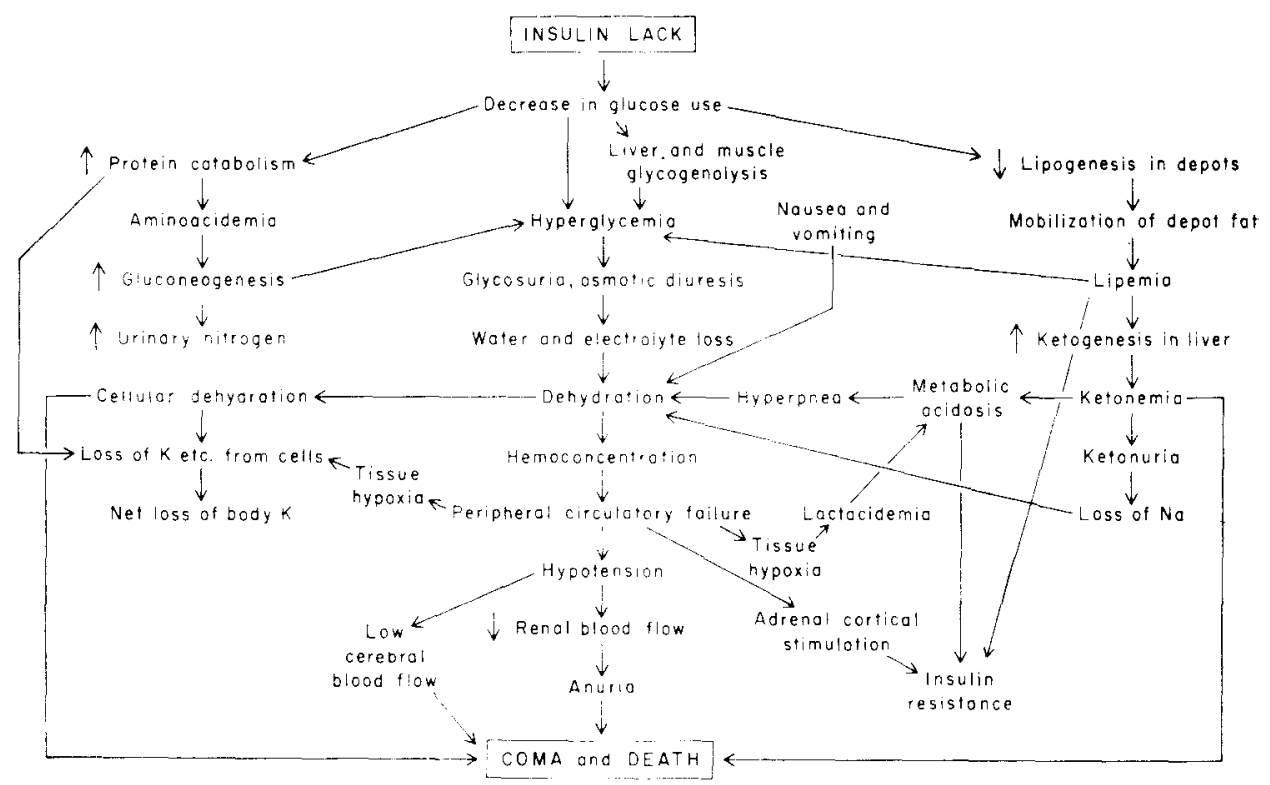

FiGcre 8. Insulin lack exerts multiple interrelated effects in protein, glucose, and lipid metabolism. (From Tepperman, J. Metabolic and Endocrine Physiology: An Introductory Text. 2nd ed., pp. 165 and 167. Chicago: Year Book Medical Publishers, Inc [1968]. By permission.)

results. So the causes of the pathophysiologic process may be multiple or varied, but the pattern of metabolic derangement seems to be a reproducible one. Success in reversing the downward trend lies in restablishing blood flow to, and oxygenation of, all of the tissues, plus infusion of glucose and insulin to inhibit lipid usage and ketosis and promote more normal cellular energy metabolism.

\section{SUMMARY}

Arterial and coronary sinus concentrations of oxygen, acid-base parameters, electrolytes, and energy-producing substrates were measured in 10 patients during and after operation for double valve replacement. The heart fibrillated during coronary perfusion in five patients and remained beating in the other five. The patterns of changes seen were largely similar to those previously found in less severely ill patients having aortic valve or congenital lesion repair, in spite of longer periods of whole-body perfusion. A case study of one patient in cardiogenic shock before operation, and with persistently low cardiac output afterward, revealed an extreme degree of metabolic and electrolytic derangement taking place.

\section{RÉSUMÉ}

Les concentrations d'oxygène des artères et des sinus coronariens, les paramètres acide-base, les électrolytes et les sous producteurs d'énergie ont été mesurés chez 10 malades pendant et après l'opération pour double remplacement de valve, à la Clinique Mayo. 
Durant la perfusion coronarienne, cinq de ces malades ont subi une fibrillation cardiaque alors que chez les cinq autres le coeur a continué de battre. Les changements observés ont été sensiblement les mêmes que ceux qu'on avait déjà vus chez des sujets moins atteints qui subissaient une réparation de valve aortique ou d'une lésion congénitale, malgré la plus longue durée de perfusion totale. L'étude spéciale d'un cas en état de choc cardiogénique avant l'opération et chez qui a persisté par la suite un faible débit cardiaque, a révélé que s'installait un très sévère dérangement métabolique et électrolytique.

\section{REFERENCES}

1. Moffitt, E. A.; Rosevear, J. W.; \& McGoon, D. C. Myocardial Metabolism in Children Having Open-Heart Surgery. J.A.M.A. 211: 1518 (1970).

2. Moffitt, E. A.; Rosevear, J. W.; Townsend, C. H.; \& McGoon, D. C. Myocardial Metabolism in Patients Having Aortic-Valve Replacement. Anesthesiology. 31: 310 (1969).

3. Severinghaus, J. W. Blood Gas Calculator. J. Appl. Physiol. 21: 1108 (1966).

4. Singer, R. B. \& Hastings, A. B. An Improved Clinical Method for the Estimation of Disturbances of the Acid-Base Balance of Human Blood. Medicine (Balt). 27: 223 (1948).

5. Barker, S. B. \& Summerson, W. H. The Colorimetric Determination of Lactic Acid in Biological Material. J. Biol. Chem. 138: 535 (1941).

6. Friedmann, T. E. \& Haugen, Gladys E. Pyruvic Acid. II. The Determination of Keto Acids in Blood and Urine. J. Biol. Chem. 147: 415 (1943).

7. Bierman, E. L.; Dole, V. P.; \& Roberts, T. N. An Abnormality of Nonesterified Fatty Acid Metabolism in Diabetes Mellitus. Diabetes. 6: 475 (1957).

8. Bloom, W. L. The Determination of Ketone Bodies in Biological Fluids. J. Lab. Clin. Med. 51: 824 (1958).

9. McGuckin, W. F. Experience With the AutoAnalyzer in the Analysis of Blood for Sugar and Urea (abstract). Clin. Chem. 5: 262 (1959).

10. WANG, C. C. Improvements in the Methods for Calcium Determination in Biological Material. J. Biol. Chem. 111: 443 (1935).

11. Rayfono, C. R.; Khouri, E. M.; Lewis, F. B.; \& GregG, D. E. Evaluation of Use of Left Coronary Artery Inflow and $\mathrm{O}_{2}$ Content of Coronary Sinus Blood as a Measure of Left Ventricular Metabolism. J. Appl. Physiol. 14: 817 (1959).

12. Moffitt, E. A.; Rosevear, J. W.; \& McGoon, D. C. Myocardial Metabolism During and After Mitral Valve Replacement. Ann. Thorac. Surg. 10: 169 (1970).

13. Bing, R. J. \& Fenton, J.C. Cardiac Metabolism. Ann. Rev. Med. 16: 1 (1965).

14. Pacifico, A. D.; Digerness, S.; \& Kirklin, J. W. Alterations in Exchangeable and Intracellular Cations Resulting From Intracardiac Surgery (abstract). Circulation. 38 Suppl. 6: 151 (1968).

15. Haved, R. J. The Autonomic Nervous System and Intermediary Carbohydrate and Fat Metabolism. Anesthesiology. 29: 702 (1968).

16. Tepperman, J. Metabolic and Endocrine Physiology: An Introductory Text. 2nd ed., pp. 165 and 167. Chicago: Year Book Medical Publishers, Ine (1968).

17. Huckabee, W. E. Relationships of Pyruvate and Lactate During Anaerobic Metabolism. r. Effects of Infusion of Pyruvate or Glucose and of Hyperventilation. J. Clin. Invest. 37: 244 (1958).

18. Triner, L.; Kypson, J.; \& Zicha, B. Effect of tham on Carbohydrate Metabolism. Ann. Anesth. Franc. 7: 593 (1966).

19. Moffrtt, E. A.; Rosevear, J. W.; Molnar, G. D.; \& McGoon, D. C. Myocardial Metabolism in Open Heart Surgery Using a Whole Blood Prime (abstract). Read at the American Society of Anesthesiologists, San Francisco, 27 October 1969.

20. Moffitt, E. A.; Rosevear, J. W.; Molnar, G. D.; \& McGoon, D. C. Myocardial Metabolism in Open-Heart Surgery: Correlation With Insulin Response. J. Thorac. Cardiov. Surg. 59: 691 (1970).

21. Leight, L.; DeFazio, V.; Talmers, F. N.; Regan, T. J.; \& Hellems, H. K. Coronary Blood Flow, Myocardial Oxygen Consumption, and Myocardial Metabolism in Normal and Hyperthyroid Human Subjects. Circulation. 14: 90 (1956). 